\title{
Milipore SIGMa
}

THE

OF

Expertise at the nanoscale SigmaAldrich.com/nanomaterials

Visit us at MRS Fall at booth \#1024

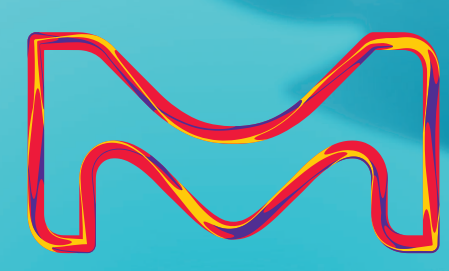

10

Als
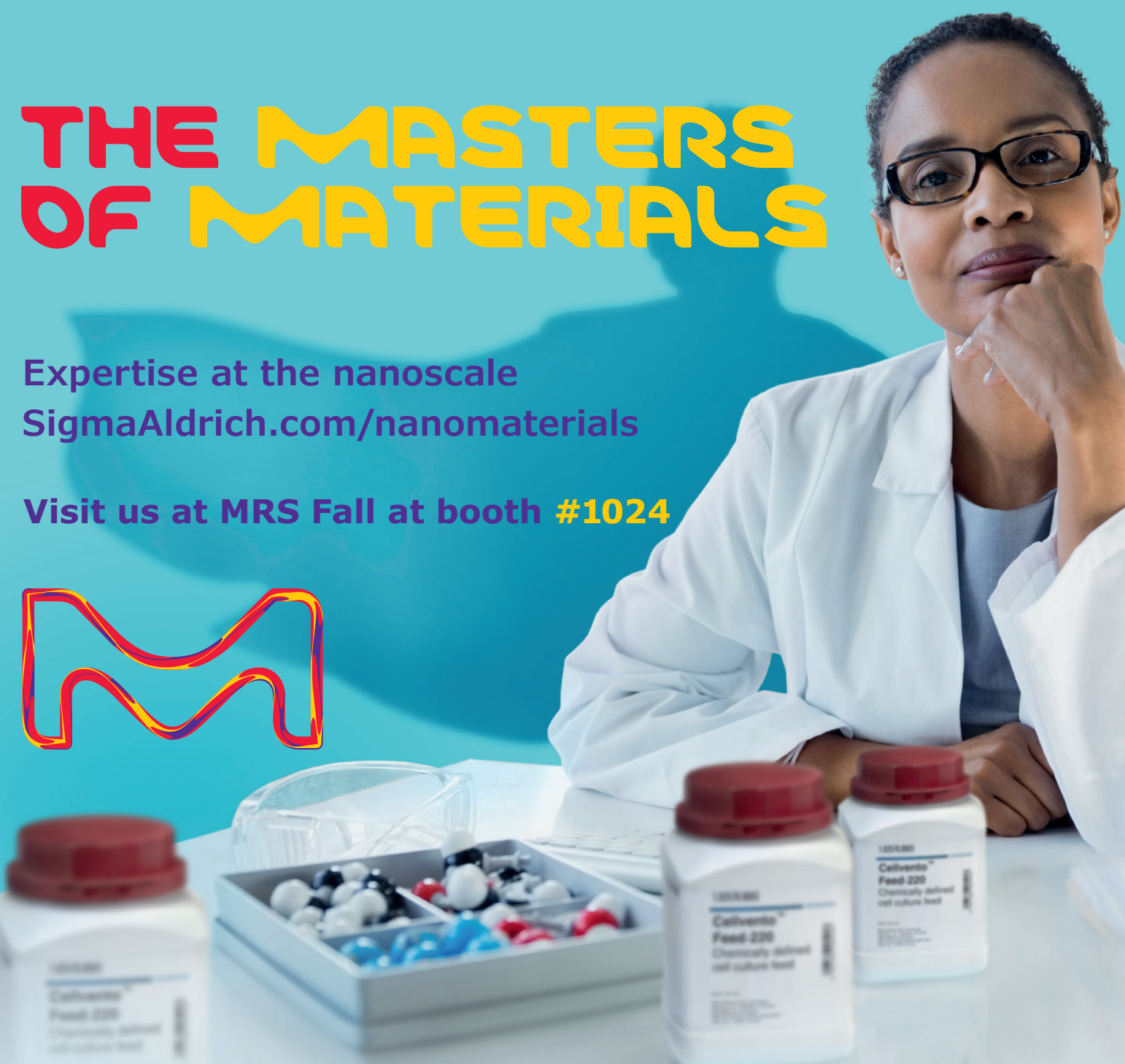

(C) 2019 Merck KGaA, Darmstadt, Germany and/or its

affiliates. All Rights Reserved. MilliporeSigma and the

Germany or its affiliates. All other trademarks are

the property of their respective owners. Detailed

information on trademarks is available via publicly

accessible resources.

2018-18940 


\section{口I A M E R I C A N

THE ADVANCED MATERIALS MANUFACTURER @

nanogels glassycarbon

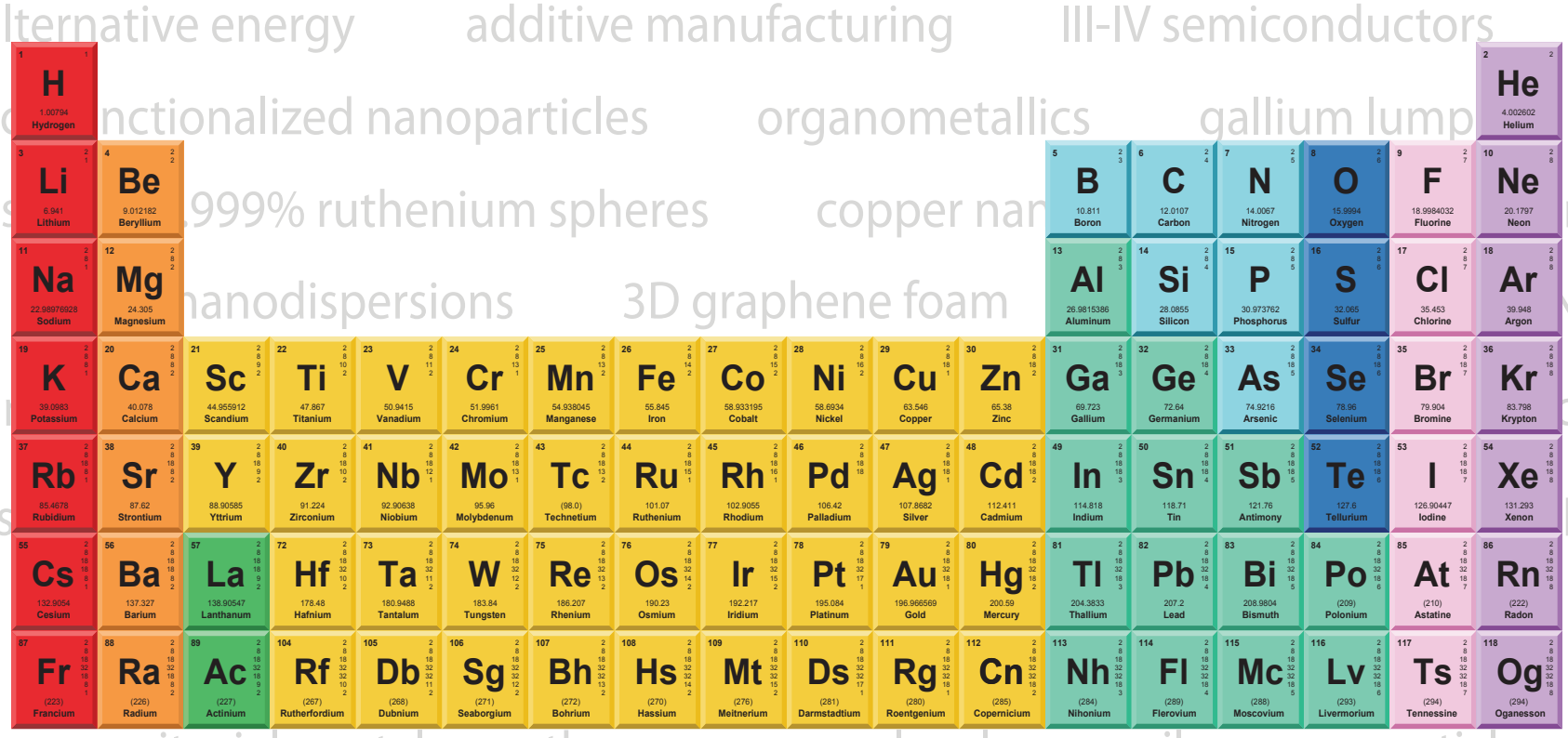

epitaxial crystal growth macromolecules

\begin{tabular}{|c|c|c|c|c|c|c|c|c|c|c|c|c|c|}
\hline $\mathrm{Ce}$ & $\mathrm{Pr}$ & 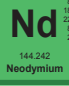 & $\mathrm{Pm}$ & 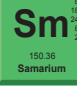 & 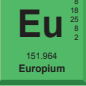 & 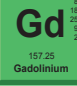 & 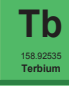 & 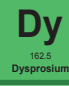 & 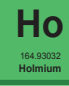 & 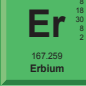 & 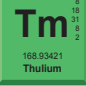 & 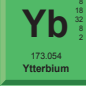 & $\begin{array}{c}\mathrm{Lu} \\
\mathrm{u}=\mathrm{u}\end{array}$ \\
\hline Th & 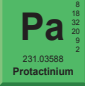 & 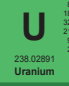 & 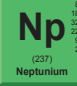 & 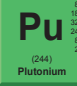 & 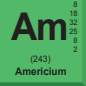 & 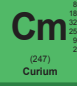 & 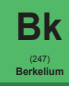 & $\underset{\substack{\text { cass } \\
\text { chandum }}}{\mathrm{Cf}}$ & $\underset{\substack{\text { Ess } \\
\text { Ensmoum }}}{\text { Es }}$ & 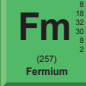 & 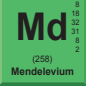 & 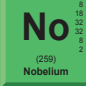 & Lr \\
\hline
\end{tabular}

transparent ceramics

\section{cerium oxide polishing powder rare earth metals \\ Now Invent."}

spintronics

mesoporus silica sputtering targets

deposition slugs

The Next Generation of Material Science Catalogs

Over 15,000 certified high purity laboratory chemicals, metals, \& advanced materials and a state-of-the-art Research Center. Printable GHS-compliant Safety Data Sheets. Thousands of new products. And much more. All on a secure multi-language "Mobile Responsive" platform. 